\title{
CONFIGURAÇÕES SUBJETIVAS DA PARTICIPAÇÃO POLÍTICA DE DIRIGENTES DO PSDB/ES
} CONFIGURACIONES SUBJETIVAS DE LA PARTICIPACIÓN POLITICA DE LOS LIIDERES DEL PSDB/ES SUBJECTIVE CONFIGURATIONS OF POLITICAL PARTICIPATION OF LEADERS OF PSDB/ES

http://dx.doi.org/10.1590/1807-03102016v28n2p278

\author{
Everton Faria Meira, Marcia Prezotti Palassi e Alfredo Rodrigues Leite da Silva
} Universidade Federal do Espírito Santo, Vitória/ES, Brasil

\section{RESUMO}

Este artigo tem por objetivo compreender as configurações subjetivas da participação política de dirigentes partidários do Partido da Social Democracia Brasileira no Espírito Santo - PSDB/ES. Adota-se uma abordagem histórico-cultural, associada à discussão sobre participação política em partidos políticos. Trata-se de um estudo de caso baseado na epistemologia qualitativa de Gonzalez Rey (2003a). Os dados foram obtidos entre abril/2011 e março/2013, por meio de questionário, redação, observação participante, conversações grupais e individuais com dirigentes do PSDB/ES. Os resultados revelam configurações subjetivas da participação política singulares, construídas em torno de aspectos como: o constrangimento em assumir a participação política; sentir-se e não sentir-se dirigente; admirar ou criticar os quadros do partido; decepções com o sistema partidário brasileiro; desejo de adequações na gestão do partido e da política no Brasil. Conclui-se que motivações, barreiras e constrangimentos dos dirigentes geram ambiguidades, levando-os ao dilema entre participar (de maneiras distintas) ou não da política.

Palavras-chave: subjetividade; configurações subjetivas; participação política; partidos.

\section{RESUMEN}

Este artículo tiene como objetivo comprender las relaciones entre las manifestaciones de configuraciones subjetivas y la participación política de los líderes del Partido da Social Democracia Brasileira en el Espirito Santo - PSDB/ES. Articula la teoría de la subjetividad y de la Epistemología y Metodología Cualitativa de González Rey (1999; 2003b; 2004; 2005), con aportaciones teóricas sobre la participación política en los partidos políticos. Los sujetos de la investigación son los líderes del PSDB/ES. Los datos se produjeron alrededor de ellos en el contexto investigado a través de conversaciones individuales y de grupo, un ensayo producido por los sujetos de investigación, cuestionario con preguntas abiertas y cerradas y observación participante. El análisis de datos se basa en identificación de los indicadores de sentidos agrupados que originó significado central. Se concluye que las manifestaciones de las configuraciones subjetivas relacionadas con la participación política revelan motivaciones, obstáculos y las limitaciones de los líderes de insertarlos en la ambigüedad que rodea el dilema entre participantes o no de la política.

Palabras clave: subjetividad; configuraciones subjetivas; participación política.

\begin{abstract}
This article aims to understand the relationships between manifestations of subjective configurations and the political participation of party leaders of the Partido da Social Democracia Brasileira in Espirito Santo - PSDB/ ES. A historical-cultural approach was adopted for this article, combined with discussion of political participation in political parties. It is a qualitative case study based on qualitative epistemology of Gonzalez Rey (2003a). The data was collected between April/2011 and March/2013 by means of questionnaire, writing, participant observation and group and individual conversations with leaders of the PSDB/ES. The results revealed subjective configurations of individual political participation, built around issues such as: the embarrassment of assuming political participation; to feel and to not feel ruling; to admire or criticize the party leaders; disappointments with the Brazilian party system; to wish for adjustments in the management of the party and politics in Brazil. In conclusion, motivations, barriers and constraints of leaders drive them to the dilemma of participate (in different ways) or not participating of politics.
\end{abstract}

Keywords: subjectivity; subjective configurations; political participation; parties. 


\section{Introdução}

Este artigo se insere no campo de estudos da participação política nos partidos políticos brasileiros. O foco da discussão se volta para as configurações subjetivas da participação política de dirigentes partidários, em um país no qual predomina a visão da política partidária como um ambiente perverso e sujeito à manipulação (Sabucedo, 1996; Bordenave, 2007; Hazan \& Rahat, 2010; Russell, 2007).

Dentre os partidos existentes, a investigação do presente artigo se voltou para a vivência de dirigentes partidários do Partido da Social Democracia Brasileira no Espírito Santo - PSDB/ES, em um período no qual ocorreu a perda de espaço do partido no estado, nas eleições municipais de outubro de 2010. Dentro dessa delimitação, este artigo tem como objetivo compreender as configurações subjetivas da participação política de dirigentes partidários do PSDB/ES.

Para atingir tal objetivo, são adotados os conceitos de configurações subjetivas e de sentidos subjetivos da Teoria da Subjetividade de González Rey (1999; 2003a; 2003b; 2004; 2005), bem como a epistemologia e metodologia qualitativa de González Rey (1999; 2003a; 2005), privilegiando-se o estudo de caso (González Rey, 1999).

A Teoria da Subjetividade (González Rey, 1999; 2003a; 2003b; 2004; 2005) foi articulada com as contribuições teóricas sobre a participação política. $\mathrm{Na}$ abordagem aqui adotada, esta última é reconhecida como um processo subjetivo, em uma concepção de subjetividade pautada numa compreensão histórico-cultural do homem (Silveira \& Palassi, 2011). Nela, os sentidos subjetivos procedentes das experiências atuais e anteriores do sujeito constituem subjetivamente sua manifestação em cada espaço social concreto.

Isso reforça a ideia de que as atividades cotidianas dos sujeitos são influenciadas por suas condições singulares de vida. Ao assumir esse entendimento, a centralização das decisões em um partido político (Duverger, 1963), a formação de oligarquias partidárias (Michels, 1949) e a própria política são consideradas produções subjetivas.

Com base em tal concepção, este artigo se aproxima da abordagem psicossociológica de estudos sobre participação política (Balbachevsky, 1992; Araújo, 2005; Castro, 2008; Castro, Pérez \& Silva, 2010; Braga \& Pimentel Jr., 2011). A partir da aproximação com essa abordagem, a discussão aqui desenvolvida trata de aspectos pouco explorados no campo de estudo em questão e que indicam a sua relevância: as configurações subjetivas da participação política de dirigentes de um partido político brasileiro, produzidas na dialética entre $o$ momento individual e social que origina diversas produções subjetivas humanas interligadas, entre elas a própria política (González Rey 2003a, 2003b, 2005).

A perspectiva adotada trata a participação política como um aspecto da vida política e da subjetividade humana que vai além da política. Ela possibilita compreender a dinâmica na qual um dirigente, com uma participação política convencional, subjetivamente, convive com diversas configurações da subjetividade que extrapolam a política, gerando dilemas em manter ou não sua participação no partido. A participação política dos dirigentes é vista como um fenômeno marcado pela complexa interligação de diversas configurações subjetivas que extrapolam a política. Portanto, a relevância deste artigo está em revelar o potencial dessa perspectiva e aplicála para compreender as configurações subjetivas da participação política de dirigentes partidários do PSDB/ES.

O levantamento dos dados deu-se entre abril de 2011 e março de 2013, através das técnicas de questionário com questões abertas e fechadas, produção de uma redação pelos sujeitos de pesquisa, conversações individuais e grupais e observação participante. A análise dos dados foi realizada mediante a identificação de indicadores de sentidos subjetivos, que, ao serem agrupados, originaram núcleos de significação, interpretados com base nos princípios da epistemologia qualitativa (González Rey, 1999, 2003a, 2005).

Os resultados da investigação empírica revelam diferentes configurações subjetivas da participação política, evidenciando constrangimentos em assumir o papel de dirigente partidário e decepções com o sistema partidário brasileiro, sugerindo adequações na gestão do partido e da política partidária no Brasil. Tais resultados indicam a relevância de se considerar a subjetividade ao tratar da temática da participação política, conforme se discutirá a seguir.

Para desenvolver tal discussão, inicialmente, descreve-se brevemente a teoria da subjetividade que é articulada com a literatura sobre a participação política. Em seguida, são apresentados os aspectos metodológicos adotados (González Rey, 2005), baseados na epistemologia qualitativa de González Rey (2003a). Por fim, os dados analisados são discutidos e, após, tecem-se as considerações finais. 


\section{A teoria da subjetividade}

Neste artigo, adotou-se a definição de subjetividade de González Rey (2005, p. IX). Para ele, a subjetividade é um sistema "complexo e plurideterminado" que sofre influências da complexa rede de relações sociais. Assim, no momento em que o sujeito desenvolve a sua atividade, emergem configurações subjetivas que são constituídas de sentidos subjetivos que se integram. Estes sentidos são definidos por González Rey (2003a) como a unidade entre o simbólico e o emocional, em que a emergência de um implica o outro sem se converter em sua causa (González Rey, 2003a).

Vervloet \& Palassi (2011, p. 314-315) esclarecem que o sentido subjetivo, segundo Gonzalez Rey (2003b), representa a forma essencial dos processos de subjetivação, já que "exprime as diferentes formas de apreensão da realidade" por meio de complexas unidades simbólico-emocionais. As autoras explicam ainda que a compreensão da subjetividade dentro dessa proposta pressupõe "a superação de toda forma reducionista e simplificadora de representação da psique, a qual não pode ser restrita aos níveis biológico e cultural da existência humana" (Vervloet \& Palassi, 2011, p. 314-315).

Assim, a proposta de uma configuração subjetiva está relacionada a uma delimitação complexa do real. Conforme Morín (2005), determinados fenômenos, como a criatividade ou a liberdade, podem ser reconhecidos mesmo em uma visão que não reconheça sua complexidade, mas, como eles ocorrem dentro de um quadro complexo, só é possível explicá-los a partir desse quadro. O pensamento simplificador não consegue explicar a complexidade da conjunção entre o individual e a sociedade, uma vez que este pensamento tende a anular a diversidade ou apresentar a diversidade sem oferecer explicações para as relações dela com a unidade, como se unidade e diversidade não coexistissem em uma mesma experiência subjetiva, articuladas em torno da objetividade e da subjetividade. Este pensamento gerou uma distorção em torno da significação do termo "subjetivo".

Tal distorção, de acordo com González Rey (2004), foi gerada na perspectiva da cognição social, e decorre da justaposição entre a experiência subjetiva interna e o mundo objetivo externo. González Rey (2004, p. 125) enfatiza que "a subjetividade não é o oposto do objetivo, é uma qualidade da objetividade nos sistemas humanos produzidos culturalmente". A partir dessa concepção de subjetividade, adota-se no presente artigo um conceito de configuração subjetiva baseada nas ideias do autor: consiste num sistema subjetivo e complexo que implica na articulação de diferentes processos, produzindo diferentes signos.

Dentre os infinitos fenômenos inseridos nesse processo de produção de signos, temos a participação política nos partidos políticos. Ao buscar contribuir com o campo de estudo da participação política, defende-se que um caminho para reconhecer a complexidade da participação política é estudar as suas configurações subjetivas, marcadas por suas especificidades, discutidas a seguir.

\section{A participação política em uma perspectiva subjetiva histórico-cultural}

Arevisão de literatura sobre a participação política nos partidos políticos permite observar o predomínio de três distintas abordagens: a abordagem sociológica de Luna (2010), Madrid (2011) e de Russell (2007), que dá ênfase a aspectos econômicos, locais, étnicos e estruturais da participação política; a abordagem psicossociológica de Balbachevsky (1992), Araújo (2005), Castro (2008), Castro, Pérez \& Silva (2010), e Braga \& Pimentel Jr. (2011), que destaca a consciência política e o processo de identificação partidária; e a abordagem racional de Jiménez (2009), Gomes (2005) e Baquero \& Gonzalez (2011), que procura medir e prever o comportamento político através de variáveis.

A discussão desenvolvida neste artigo se aproxima da abordagem psicossociológica, em uma ótica na qual se busca, por meio da teoria da subjetividade, salientar as singularidades. Essas singularidades evidenciam como as configurações subjetivas de toda atividade humana são diferentes e impossíveis de se padronizar. Dessa maneira, a teoria rompe com as dicotomias que limitam a subjetividade ao intrapsíquico considerando-a na dialética entre o momento individual e social. Para Silveira \& Palassi (2011), o conceito de subjetividade social supera a separação entre o individual e o social. Além disso, tal conceito realça que esses espaços não podem ser vistos de forma fracionada.

Nessa perspectiva, o sujeito é simultaneamente uma singularidade e um ser social. Ele está implicado na configuração subjetiva da ação do outro, recuperando o seu caráter dialético e complexo (González Rey, 2003a). As noções de subjetividade e de sentido subjetivo permitem conceber que as produções do sujeito estão presentes na construção do tecido social (Neubern, 2014). A dialética entre o individual e o social possibilita compreender a condição singular do sujeito, "possível somente a partir da compreensão 
do caráter subjetivo da sua constituição psicológica" (González Rey, 2003a, p. 70). Segundo González Rey (2003a), é preciso enxergar o sujeito, a cultura e a subjetividade como fenômenos diferentes que se relacionam e se integram em momentos qualitativos do cotidiano.

No presente artigo, o cenário desse momento é um partido político, que é apresentado por Araújo (2005) como uma organização relativamente recente, e que vem se adequando aos imperativos dos diferentes contextos a que se vincula (Ibañez \& Iñiguez, 1996). Esta capacidade do partido de se adequar a tais imperativos conduz a uma reflexão sobre a participação política das pessoas que dele participam. Entretanto, nos últimos anos, essa adequação se dá em um contexto no qual a maioria das pessoas atribui à política partidária características negativas, como a perversidade e a manipulação (Bordenave, 2007; Hazan \& Rahat, 2010; Russell, 2007; Sabucedo, 1996).

Em parte, essas e outras atribuições se relacionam com o abandono dos canais convencionais de participação política, ao afastamento dessa participação ou à adesão aos canais não convencionais de participação (canais como manifestações ilegais ou postagem em redes sociais que, com mudanças nas convenções sociais, podem passar a ser considerados convencionais). Trata-se de um processo que não acontece de modo linear e constante, visto que qualquer atividade humana envolve aspectos que vão além da simples instrumentalidade racional. O estudo de Hazan \& Rahat (2010), por exemplo, discute as implicações do distanciamento entre os cidadãos, as instituições (partidos políticos) e os processos (eleições) no incremento da participação política por meio de canais não convencionais.

A participação política, nessa perspectiva, é considerada um aspecto da vida política que implica em configurações diversas da subjetividade humana, não apenas restritas à política, já que a própria política é uma produção subjetiva (González Rey, 2003a; 2003b; 2005). Nessa ótica, os dirigentes que, adeptos à participação política convencional, também lidam com as possibilidades de não participarem ou de participarem de maneira não convencional, e com outras configurações da subjetividade que vão além da política. Portanto, para abordar a participação política desses dirigentes, foco do presente estudo, é necessário adotar um caminho que permita ir além da instrumentalidade racional e que alcance tal complexidade. Nesse sentido, foi adotada, neste artigo, a epistemologia qualitativa de González Rey, que embasou as escolhas metodológicas exibidas a seguir.

\section{Aspectos metodológicos do estudo}

A pesquisa adotou uma abordagem qualitativa, fundamentada na epistemologia qualitativa proposta por González Rey (2003a, 2004, 2005). A investigação empírica teve início com a vivência de um dos autores deste artigo junto a dirigentes e militantes do PSDB/ ES, iniciada em abril de 2011 e que se estendeu até março de 2013, período durante o qual o pesquisador registrou suas observações em um diário de campo.

O cenário de pesquisa (González Rey, 2005), espaço social que caracteriza o desenvolvimento da pesquisa e que está orientado a promover o envolvimento dos participantes, foi criado ao longo do período citado anteriormente. Em conjunto com a vivência, o cenário de pesquisa foi criado com o envio de um e-mail às 75 pessoas que faziam parte do diretório do PSDB (membros titulares e suplentes do diretório estadual, bem como do conselho fiscal e do conselho de ética), no início de 2013. Nesse e-mail havia um documento com informações sobre a pesquisa, a solicitação de uma redação com o tema "Por que sou militante do PSDB?" e um questionário com perguntas abertas sobre a vida partidária, pessoal e profissional, além de perguntas fechadas sobre a vida pessoal deles.

O questionário e a redação foram utilizados na pesquisa para facilitar as expressões do sujeito e se complementavam entre si. Apenas quatro pessoas responderam o questionário, constituindo-se nos sujeitos, após a assinatura do Termo de Consentimento Livre e Esclarecido.

Para ampliar o envolvimento dos sujeitos de pesquisa com a pesquisa, a metodologia qualitativa de González Rey (2005) propõe sistemas conversacionais em que o pesquisador substitui o lugar-central das perguntas pela dinâmica da conversação sobre um tema. Portanto, foram realizadas conversações individuais e em grupo com os sujeitos.

$\mathrm{Na}$ conversação individual, foi solicitado que falassem abertamente acerca de como se deu a sua filiação ao PSDB. Em seguida, foram promovidas três conversações em grupo, com o intuito de explorar o potencial dessa técnica em produzir conhecimento sobre o contexto dos sujeitos a partir da interação entre eles, e não apenas entre sujeito e o pesquisador, como ocorre na conversação individual.

A análise dos dados consistiu em um processo construtivo interpretativo que teve início quando o pesquisador se inseriu no contexto da pesquisa. Foram identificados indicadores de sentidos relativos ao 
objetivo proposto, que foram agrupados e deram origem a núcleos de significação, revelando as implicações do sujeito com a realidade estudada (Gomes \& Souza, 2014). Esses indicadores e as representações identificadas pelo pesquisador representam um modelo teórico em construção, tratado como um modelo hipotético.

De acordo com a metodologia adotada, esse modelo hipotético não possui significação estatística, ele consiste em um texto que constitui a base de um conhecimento em construção (González Rey, 2005). O modelo foi gerado por meio da constante revisão dos relatos dos sujeitos e na comparação com informações obtidas nos diversos instrumentos. Para González Rey (2005), o processo de construção do modelo é um processo vivo, no qual o pesquisador é o núcleo gerador de pensamento e parte inseparável do curso da pesquisa que constrói os resultados progressivamente, conforme a sua reflexão teórica, em um processo construtivo interpretativo do conhecimento.

Neste estudo, a participação ativa dos sujeitos de pesquisa nesse processo de construção do modelo se deu principalmente por meio das conversações. $\mathrm{Na}$ primeira conversação em grupo, discutiu-se a participação política de cada um no PSDB/ES. A partir da análise dos dados obtidos até essa etapa, foi proposto um modelo teórico em construção (tratado como uma hipótese ou um modelo hipotético), com base em indicadores das configurações subjetivas e em representações identificadas pelo pesquisador. $\mathrm{O}$ referido modelo foi discutido com os sujeitos de pesquisa em uma segunda conversação em grupo. Em seguida, os dados foram analisados e o modelo teórico foi alterado baseado na produção conjunta entre pesquisador e sujeitos de pesquisa. Esse modelo foi discutido na terceira conversação grupal que o legitimou.

Os indicadores constitutivos do modelo hipotético legitimado diziam respeito aos seguintes aspectos: o tempo de filiação; como enxergam a família; os cargos comissionados já exercidos; os referenciais de esquerda e de direita e o PSDB como partido de massas ou de quadros; como cada um avalia o eleitor tucano; a avaliação das ideias do PSDB; o instrumentalismo do PSDB; a avaliação do PT; o impacto do fracasso do governo do PSDB no Espírito Santo (1999/2003) sobre o partido; e como vislumbram o futuro desse estado.

A seguir, são apresentados os resultados da pesquisa construídos a partir desses indicadores. Vale ressaltar que os nomes dos sujeitos da pesquisa são fictícios para preservar a identidade deles.

\section{O PSDB/ES como um cenário socialmente construído}

Para discutir a participação política dos dirigentes partidários no PSDB/ES, faz-se necessário descrever o contexto em que esta participação é construída. A literatura sobre o PSDB discute predominantemente a história do partido em nível nacional. Lahuerta (2001) entende que a origem intelectual do PSDB se deu no Centro Brasileiro de Análise e Planejamento - CEBRAP, já a origem política do partido, segundo Sanchéz (2003), é o Movimento Unidade ProgressistaMUP. De maneira mais específica, o PSDB foi fundado em 25 de junho de 1988 e, de acordo com informações divulgadas pelo Tribunal Superior Eleitoral no seu website, em setembro de 2013 o partido tinha 1,35 milhões de filiados em todo o país. Conforme dados disponíveis no website oficial do partido, naquele mês, o PSDB governava oito estados e possuía em seus quadros 48 deputados federais e 11 senadores.

Em termos de estrutura partidária, o PSDB é um partido verticalizado. Isso fica evidente diante da clássica separação entre partidos de massa e partidos de quadros proposta por Duverger (1963), com base na qual Roma (2006, p. 163) destaca que as características do PSDB apontam para um partido de quadros, pois é um partido constituído sob seus líderes "com falta de participação dos demais membros do partido". Entretanto, a estrutura partidária não é suficiente para explicar o fenômeno da participação política em todas as suas manifestações. Defende-se que dentro do mesmo partido, com a sua estrutura partidária, é possível encontrar pessoas que configuram sua participação política das maneiras singulares, a partir de determinadas configurações subjetivas que se relacionam com o partido (González Rey, 2003a, 2003b, 2005). Tais configurações e as suas implicações para a participação política no PSDB/ES serão abordadas a seguir.

\section{Configurações subjetivas da participação política dos dirigentes do PSDB/ES}

Participaram da pesquisa que gerou este artigo três homens e uma mulher, sendo os homens com idade entre 58 e 67 anos, e a mulher com 24 anos. Dois homens estavam filiados ao partido há doze anos, o outro há dezoito anos e a mulher há três anos. Os três homens foram criados no meio urbano, enquanto a mulher tem sua origem no interior do Espírito Santo. Os nomes fictícios adotados são Guilherme, Miguel, Marcelo e Juliana. Apesar de suas distintas histórias de 
vida, todos alegam ter se filiado ao partido por causa do programa partidário e pela admiração por figuras ilustres como o ex-presidente Fernando Henrique Cardoso.

Guilherme está filiado ao PSDB há mais de dez anos e alega ter se filiado por causa do programa partidário. Lamenta ter pouco tempo para militar no partido e culpa o Partido dos Trabalhadores - PT pelo momento de crise que todos os partidos brasileiros atravessam: "Porque o PT está há 11 anos no poder ... Tá essa bagunça. Ai ele arrasta sobre os outros partidos a descrença sobre a política. E nós não temos educação e ninguém lê política" (Guilherme, primeira conversação grupal).

A rivalidade entre o PT e o PSDB pode ser observada nas últimas eleições presidenciais. Para Limongi \& Guarnieri (2014), o PT e o PSDB estabeleceram um verdadeiro duopólio eleitoral. Conforme Limongi \& Guarnieri (2015), para cada par de eleições pode se construir uma matriz de transição de votos entre eleições consecutivas: perdas e ganhos entre partidos se anulam e o sucesso do PT é o fracasso do PSDB e vice-versa. Tal rivalidade entre os dois partidos reforça a crise do sistema político em geral, estudada por Russell (2007) e por Hazam \& Rahat (2010). Assim, Guilherme acredita que os políticos são mal vistos e, a partir daí, são produzidos diferentes sentidos subjetivos que vão se configurar na forma como ele lida com os amigos: sempre evitando conversar sobre política para não sofrer. Na primeira conversação grupal, ele afirmou: "A gente não discute política... ninguém quer discutir política. Futebol, filme, viagens... então não tem jeito".

Uai, você acha que eu já não ouvi?' 'Pô... Você ainda tá na política? Você tá levando quanto? Onde você tá agora?'... Eu ouço cara... As pessoas que me conhecem bem me falam isso... Sabem quem eu sou... Eu falo pra todo mundo: 'eu não dependo disso pra viver'... Nunca dependi... Eu nunca dependi de cargo político. (Guilherme, terceira conversação grupal)

Neste ponto, observa-se a criação de um campo de sentidos subjetivos caracterizado por sua produção pessoal, pela afetividade e pelos desdobramentos de sua narrativa, pela emotividade e por seus valores. Apesar de Guilherme não admitir diretamente que se sente constrangido em assumir sua participação política, tal constrangimento fica subentendido neste campo de seus sentidos subjetivos. É possível notar que a atividade da participação política e o sentimento de constrangimento em assumir esta participação se relacionam de modo que a atividade afeta o sentimento e vice-versa, sem que um se converta na causa do outro.
Nessa relação dialética entre a atividade e as emoções, emergem as configurações subjetivas. González Rey (2005, p. 136) assinala que a geração de campos de sentidos subjetivos "é uma necessidade para a construção de configurações subjetivas por parte do pesquisador". A configuração subjetiva da participação política de Guilherme é marcada por vergonha e desencanto. Ele mantém um posicionamento de princípios, mas se sente decepcionado com a política no Brasil. Esta representação negativa da atividade política é capaz de integrar tanto sua participação política, quanto a rejeição a essa participação que ele atribui aos seus amigos. Essa configuração é singular, mas apresenta aspectos comuns, assim como aspectos distintos da configuração subjetiva de outros dirigentes investigados, como o Miguel.

Miguel está filiado no PSDB há mais de uma década. Um sentido subjetivo que diferencia de forma singular o seu posicionamento é: ele se considera um técnico e trata este viés técnico como a antítese de um viés político, que ele alega não possuir. Isso constitui um indicador do seu posicionamento frente ao partido político. Como os indicadores são cadeias de significação (González Rey, 2005), a partir deles foi possível identificar que em Miguel a dualidade entre o técnico e o político na participação política era algo relevante. Na conversação individual, isso ficou claro quando Miguel afirmou: "Toda a minha história de vida, sob o ponto de vista econômico, foi construida basicamente no mercado privado", ou ainda que "acabei ingressando no PSDB primeiro como mero militante mesmo, e depois também como funcionário compondo o corpo técnico de autarquias".

Outro aspecto importante são os indicadores sobre as expectativas de Miguel a respeito de sua participação em instâncias governamentais do estado, a partir de sua participação política no PSDB, ele argumenta: "Terei grande prazer de me engajar [no governo] caso para isso venha a ser convidado" (Miguel, redação). Associada a essa expectativa, ele indica sua militância ligada a um candidato ao Poder Executivo: "Agora quando o Luiz Paulo [candidato derrotado à prefeitura de Vitória pelo PSDB em 2010] se candidatou, eu atuei na campanha... subi morro com ele, desci morro... nem tanto quanto eu queria, mas subi... porque ele me dava condição pra subir com ele, chegar com ele lá". Observa-se o sentido subjetivo de que a condição necessária para a sua militância é a de que o líder político dê condição para que ele possa estar junto na caminhada rumo ao poder.

Esta preferência e opção por formas convencionais de participação política (Russell, 2007; Hazam \& Rahat, 2010) se relaciona com a 
configuração subjetiva na qual os sentidos subjetivos levam os sujeitos a atribuírem a tais formas a condição de legítimas. Subjetivamente elas são consideradas por eles as verdadeiras formas de participação política. Todavia, cabe mencionar que a definição do que é ou não participação convencional depende da convenção social em construção (Sabucedo, 1996), portanto não é algo estático, mas possui certa estabilidade nas relações que envolvem a referida configuração subjetiva. Isso revela o potencial da abordagem aqui adotada em esclarecer os aspectos subjetivos da participação política. Essa configuração marca a atuação dos dois primeiros sujeitos e os diferencia de outro dirigente, o Marcelo.

Marcelo é o sujeito da pesquisa com idade mais avançada e está filiado ao PSDB há quase duas décadas. A forma como ele encara a idade é influenciada por sua participação política. Ele participa de redes sociais, lê blogs, posiciona-se em diversos grupos de discussão, o que foi citado por ele como um diferencial em relação às pessoas que estão na sua faixa etária. Este é um indicador do seu caráter ativo frente às mudanças que vêm ocorrendo na forma de participar politicamente. Estas mudanças para modalidades não convencionais de participação política (Hazam \& Rahat, 2010; Russell, 2007), neste caso para as redes sociais, vão acontecendo de forma gradual, na medida em que ele se distancia dos fóruns de decisão partidária.

As representações de Marcelo sobre sua participação política no partido constituem um indicador de sua relação com o tecido simbólico-emocional e relacional que existe no seu entorno (González Rey, 2004). "Eu não vou sair do PSDB porque pra alguns companheiros podem entender até como uma afronta" (Marcelo, primeira conversação grupal). "Gosto do Luiz Paulo, gosto do Emanuel [vereador eleito pelo PSDB], seremos sempre amigos, mas politicamente [gestual negativo com a cabeça]" (Marcelo, segunda conversação grupal). Aqui, percebe-se que o seu afastamento ocorre por conta de divergências políticas com dirigentes regionais do partido. Em outro momento desta primeira conversação grupal, Marcelo questionou: "Por que às vezes não vai haver uma eleição para o PSDB? Porque ele tem que atender o grupo político majoritário que tá lutando." Sobre tais problemas, ele afirma: "Ai o que que isso gera? $O$ afastamento de pessoas que pensam como eu." (Marcelo, primeira conversação grupal). Essa expressão e a sua valoração dos "companheiros" de atividade política, unido ao seu juízo crítico sobre o modus operandi do Partido, são um indicador de que ele está envolvido com a política e de que o fazer política integra sentidos subjetivos importantes de sua vida.
Nos relatos de Marcelo, pode-se perceber o seu afastamento das decisões tomadas no partido. Subjetivamente ele não se sente um dirigente partidário, porém o espaço simbólico-emocional e relacional construído por ele e por seus amigos envolve outros sentidos subjetivos que o impedem de deixar o partido. Neste caso, é possível notar os mesmos elementos que compõem o modelo da participação de Guilherme (o partido, os amigos, sentir-se ou não dirigente partidário), mas atuando de modo diferente. No tocante aos amigos, tanto nas manifestações de Guilherme quanto nas de Marcelo fica clara a relação da configuração subjetiva da amizade, que vai além da política, com a configuração subjetiva da participação política. A despeito desse elo comum, a singularidade entre eles se manifestou nos diferentes sentidos subjetivos que mediam a relação entre as duas configurações subjetivas. Enquanto para o primeiro o sentido o leva a rejeitar a participação, para o segundo é o que a mantém nela. Isso ocorreu de maneira semelhante com os sentidos subjetivos em torno do partido e do sentir-se ou não dirigente partidário, mas, nesse caso, ambos estão diretamente relacionados com a política. Isso evidencia o caráter singular na construção da experiência participativa do Marcelo e do Guilherme e revela a diversidade de configurações subjetivas em torno da participação política dos dirigentes.

Tal singularidade foi observada também na participação política de outra dirigente, a Juliana. Em seus relatos, é possível verificar sua admiração pelos dirigentes nacionais do partido. Contudo, a sua admiração pelos dirigentes nacionais do PSDB combina-se com a crítica, mesmo que seguida por tolerância, sobre erros dos dirigentes regionais. Ela admite, por exemplo, que o Conselho de Ética só foi acionado quando interessou à Executiva Regional do partido. Neste sentido, é explícita a tolerância do partido com interesses de grupos dentro do partido, reforçando a formação de oligarquias em seu interior (Michels, 1949). Entretanto, subjetivamente, Juliana redime o partido ao justificar esse fato quando afirma que o partido "é feito por homens", logo, erros e distorções de conduta fazem parte do cotidiano partidário, pois as pessoas erram.

As suas representações acerca do PSDB possuem relação direta com o seu campo de atuação: a juventude do partido, espaço simbólico-relacional (González Rey, 2004) no qual Juliana constrói sua participação política. Na primeira conversação grupal, ela manifesta o seu repúdio a uma prática comum na juventude do PSDB: "A pessoa utiliza a juventude pra poder ter influência nas decisões dentro do partido". 
Essa crítica ao contexto da juventude local, bem como as que ela tece sobre os dirigentes locais, se apresenta em contraposição à admiração que ela nutre pelos dirigentes nacionais, o que acaba por afastá-la do partido em nível local, o que, na prática, afasta-a do partido como um todo.

Subjetivamente ela se insere na construção do sentido subjetivo de que não se sente dirigente e se refere ao dirigente partidário em terceira pessoa, como se ela não fosse um deles. Em suas palavras: "Diante de greves fora do normal e uma corrupção descontrolada, o dirigente partidário não aproveita para inserir debate nos grupos organizados para disseminar a ideologia social democrata" (Juliana, redação). Em outro momento, Juliana coloca sua participação pessoal no PSDB como ativa e importante por ela se preocupar em disseminar a ideologia social democrata.

Dessa forma, Juliana evidencia sentidos subjetivos ambíguos (a admiração pelos dirigentes nacionais do partido; a crítica e a tolerância aos erros dos dirigentes; o repúdio à busca por influenciar as decisões do partido; não se sentir dirigente; a preocupação em disseminar a ideologia social democrata) que a envolvem no dilema da busca por alternativas para construir sua participação ou sua não participação.

Esse dilema entre participar ou não da política, também produzido de diferentes maneiras por Guilherme, Miguel e Marcelo, mostra-se como uma característica básica das configurações subjetivas da participação política dos dirigentes. Tal característica envolve diferentes críticas dos sujeitos ao contexto político, ao papel do dirigente, bem como suas representações e expectativas sobre o que alcançar com a política e as reações dos grupos sociais nos quais se inserem. Não há aqui uma relação simplista em que os grupos sociais (familiares; amigos; demais dirigentes; políticos; demais membros da sociedade) determinam a participação, mas subjetivamente eles são considerados e de maneiras distintas.

Foi possível observar a participação política afetando as relações pessoais e criando barreiras para discutir temas políticos com amigos e família; as relações pessoais dentro do partido impedindo o dirigente de deixá-lo; a participação impulsionada por uma ideologia social democrata. As configurações subjetivas revelaram diferentes modos de participação política, convencionais ou não. Nota-se que, mesmo quando a representação negativa da participação política se manifesta, ela surge deslocada do contexto que a sustenta: como Juliana evidencia ao louvar os líderes nacionais do partido e afastá-los de suas críticas sobre o que ocorre localmente.
Como defendem Paes de Paula e Palassi (2007), ficou claro, no contexto pesquisado, um conjunto de relações no qual o partido político se apresenta como espaço de produção de subjetividades, ainda que o controle seja um dos elementos presentes. Esse controle tanto submete os sujeitos ao seu julgo, quanto é submetido à crítica e à reação dos sujeitos que não são simplesmente passivos a ele.

Esse entendimento permite questionar o valor heurístico das teorias que buscam conteúdos universais para explicar o que leva à participação política, por exemplo (Gomes, 2005; Jiménez, 2009; Russell, 2007). A participação política deve ser considerada como uma configuração subjetiva que se entrelaça em diversas áreas da vida de cada um, com os múltiplos grupos sociais em que estão inseridos e às múltiplas escolhas que cada um faz no seu cotidiano. Entre os sujeitos pesquisados, a despeito das ambiguidades que envolvem o dilema entre participar ou não da política, cada um encontrou alternativas e justificativas para continuar participando. Tais alternativas e justificativas evidenciadas neste estudo indicam que não é apenas na política que os sujeitos encontram motivos para participar politicamente, isso surge de construções sociais na relação dialética entre sujeito e sociedade que vão muito além da política.

\section{Considerações finais}

Este artigo teve como objetivo compreender as configurações subjetivas da participação política de dirigentes partidários no PSDB/ES. Foi observado que cada dirigente partidário apresentou indicadores de características singulares (constrangimento em assumir sua participação política, sentir-se e não sentirse dirigente do partido, admirar ou criticar os quadros partidários, etc.) que parecem empurrá-los tanto para a participação política no partido quanto para não participar. Tais observações só puderam ser feitas por causa da metodologia qualitativa (González Rey, 2005), já que elas não são evidenciadas na expressão direta e consciente dos participantes da pesquisa, mas surgem do confronto dessas expressões entre o pesquisador e o pesquisado e entre eles próprios, ao serem confrontados com essas produções.

$\mathrm{O}$ constrangimento relacionado à participação política e a decepção com o sistema partidário não parecem formar configurações subjetivas isoladas, mas uma mesma configuração subjetiva em Guilherme que contém, também, o que o faz permanecer participando. No caso dele, a configuração subjetiva da participação política indica um forte sentido de alteridade (nós os dirigentes e eles que nos criticam) que, como foi dito, 
empurra esta participação política em direções opostas ("assumir sua participação" ou "sair fora disso").

No caso de Juliana, há indicadores de que a instrumentalização do conselho de ética e a centralização das decisões partidárias no partido provocam nela uma sensação de que ela está fora do processo decisório, não faz parte da oligarquia (Michels, 1949), está fora do petit comiteé (Duverger, 1963). Por outro lado, ela não admite que essa estrutura de poder se reproduz em nível nacional e mantém sua participação sustentada na defesa da ideologia social democrata e das lideranças nacionais, por compartilhar a mesma ideologia.

Sobre esse aspecto, cabe destacar que, ao privilegiar a tomada de decisões em petit comitée (Duverger, 1963), a militância deixa de ser capaz de criar obstáculos para que os parlamentares executem suas estratégias (Roma, 2006). Isso tem como consequência ignoraro potencial dos sujeitos singulares de contribuírem para o partido, transformando-os em operadores de decisões já tomadas.

No que tange à contribuição para a literatura acerca da participação política, o conhecimento produzido no presente artigo evidencia o potencial de uma abordagem que não trata essa participação de maneira instrumentalizada e objetivada. A visão da participação objetivada e medida através de questionários e outros instrumentos, defendida por autores como Monteiro, Almeida \& Vasconcelos (2012) e Piccoli \& Godoi (2012), a despeito de oferecer potencial para análises por meio de amostragens estatísticas, não permite o aprofundamento necessário para se tratar da complexidade que envolve as configurações subjetivas da participação política.

A maneira como as configurações subjetivas da participação política foram reveladas neste artigo mostra caminhos que possibilitam o reconhecimento dessa complexidade. Através desses caminhos, é possível se aprofundar no que foi aqui identificado como a ambiguidade que envolve o dilema entre participar ou não da política. Ou seja, romper com a visão dicotômica de que ou o sujeito decide participar ou decide não participar, para um entendimento no qual as duas movimentações coexistem, como tensões com as quais cada sujeito em uma sociedade com instâncias organizadas de participação política tem que lidar, pois existem infinitas maneiras de participar politicamente, com diferentes níveis de engajamento.

Este estudo tratou apenas dos dirigentes de partidos, isto é, ele focou sujeitos já participantes ativos de um partido político, que também manifestaram a tensão da não participação ou de participar menos ativamente. Portanto, defende-se que estudos futuros assumam a superação dessa dicotomia em pesquisas com sujeitos inseridos em outro contexto, e que nunca participaram de um partido político, para que se possa compreender a tensão entre manter participações políticas menos ativas ou participar mais ativamente. Por esse caminho é possível contribuir para a compreensão dessa dinâmica e de suas implicações para a sociedade.

\section{Referências}

Araújo, C. (2005). Partidos políticos e gênero: mediações nas rotas de ingresso das mulheres na representação política. Revista de Sociologia e Politica, 24, 193-215.

Balbachevsky, E. (1992). Identidade partidária e instituições políticas no Brasil. Lua Nova, 26, 133-165.

Baquero, M. \& Gonzalez, R. S. (2011). Eleições, estabilidade democrática e socialização política no Brasil: análise longitudinal da persistência de valores nas eleições presidenciais de 2002 a 2010. Opinião pública, 17(2), 369399.

Bordenave, J. E. D. (2007). O que é participação ( $8^{\mathrm{a}}$ ed.). São Paulo: Brasiliense.

Braga, M. S. S. \& Pimentel, J. (2011). Os partidos políticos brasileiros realmente não importam? Opinião Pública, 17(2), 271-303.

Castro, L. R. (2008). Participação política e juventude: do malestar à responsabilização frente ao destino comum. Revista de Sociologia e Política, 16(30), 253-268.

Castro, L. R., Pérez, B. C., \& Silva, C. F. S. (2010). Trabalho solidário: em busca de outros valores para a participação política. Praia Vermelha, 19(1), 109-124.

Della Porta, D. (2003). Introdução à ciência política. Lisboa: Editorial Estampa.

Duverger, M. (1963). Political parties. Londres: Science Editions.

Gomes, W. (2005). Democracia digital e o problema da participação civil na decisão política. Revista Fronteiras: estudos midiáticos, 7(3), 214-222.

Gomes, C. \& Souza, V. L. T. (2014). Os sentidos da inclusão escolar: reflexões na perspectiva da psicologia históricocultural a partir de um estudo de caso. Psicologia, 16(3), 172-183.

Gomes, C. G. \& Conceição, M. I. G. (2014). Sentidos da trajetória de vida para adolescentes em medida de liberdade assistida. Psicologia em estudo, 19(1), 47-58.

González Rey, F. L. (1999). La Investigación cualitativa en psicología: rumbos y desafios. São Paulo: Educ.

González Rey, F. L. (2003a). Epistemología cualitativa y subjetividad. São Paulo: Educ.

González Rey, F. L. (2003b). Sujeito e subjetividade: uma aproximação histórico-cultural. São Paulo: Pioneira Thomson Learning.

González Rey, F. L. (2004). O social na psicologia e a psicologia social: a emergência do sujeito. Petrópolis, RJ: Vozes.

González Rey, F. L. (2005). Pesquisa qualitativa e subjetividade: os processos de construção da informação. São Paulo: Pioneira Thomson Learning.

González Rey, F. L. (2011). Subjetividade e saúde: superando a clínica da patologia. São Paulo: Cortez. 
Greene, S. (2004). Social identity theory and party identification. Social Science Quarterly, 85(1), 136-156.

Hazan, R. \& Rahat, G. (2010). Democracy within parties: candidate selection methods and their political consequences. Oxford: Oxford University Press.

Ibañez, T. \& Iñiguez, L. (1996). El poder y los sistemas políticos. In J. Seoane \& A. Rodriguéz (Eds.), Psicología política (pp. 331-358). Madri: Editorial Síntesis.

Jiménez, A. R. (2009). Women and decision-making participation within rightist parties in Portugal and Spain. Análise social, XLIV(191), 235-263.

Lahuerta, M. (2001). Intelectuais e resistência democrática: vida acadêmica, marxismo e política no Brasil. Cadernos Arquivos Edgard Leuenroth, 8(14/15), 56-92.

Limongi, F. \& Guarnieri, F. (2014). A base e os partidos: as eleições presidenciais no Brasil pós-redemocratização. Novos Estudos, 99, 5-24.

Limongi, F. \& Guarnieri, F. (2015). Competição partidária e voto nas eleições presidenciais no Brasil. Opinião pública, 21(1), 60-86.

Luna, J. P. (2010). Segmented party voter linkages in Latin America: the case of the UDI. Journal of Latin American Studies, 42(2), 325-356.

Madrid, R. (2011). Ethnic proximity and ethnic voting in Peru. Journal of Latin American Studies, 43(2), 267-297.

Michels, R. (1949). Political parties. New York: Free Press.

Monteiro, S. C., Almeida, L. S., \& Vasconcelos, R. M. C. F. (2012). Abordagens à aprendizagem, autorregulação e motivação: Convergência no desempenho acadêmico excelente. Revista Brasileira de Orientação Profissional, 13(2), 153-162.

Morín, E. (2005). Introdução ao pensamento complexo. Porto Alegre: Sulina.

Neubern, M. S. (2014). Subjetividade \& complexidade na clínica psicológica: superando dicotomias. Fractal, 26(3), 835-852.

Paes de Paula, A. P. \& Palassi, M. P. (2007). Subjetividade e simbolismo nos estudos organizacionais: um enfoque histórico cultural. In A. P. Carrieri \& L. A. S. Saraiva, Simbolismo organizacional no Brasil (pp. 119-228). São Paulo: Atlas.

Piccoli, P. \& Godoi, C. K. (2012). Motivação para o trabalho voluntário contínuo: uma pesquisa etnográfica em uma organização espírita. Organizações \& Sociedade, 19(62), 399-415.

Roma, C. (2006). Organizaciones de partido en Brasil: el PT y el PSDB bajo perspectiva comparada. America Latina Hoy, 44, 153-184.

Russell, A. (2007). Political Parties as Vehicles of Political Engagement. Parliamentary Affairs, 58(3), 555-569.

Sabucedo, J. M. C. (1996). Participación política. In Psicologia Politica (pp. 85-97). Madri: Editorial Síntesis.

Sanchéz, R. C. (2003). De volta ao começo! Raizes de um PSDB militante que nasceu na oposição. Brasília, DF: Instituto Teotônio Vilela.

Silveira, R. Z. \& Palassi, M. P. (2011). A vida na fazenda: sentidos subjetivos do servidor fazendário ante a participação no trabalho. Revista de Administração Mackenzie, 12(6), 192-223.
Vervloet, A. M. P. \& Palassi, M. P. (2011). Eleições, mesários e subjetividade: reflexões sobre a produção de sentidos subjetivos a partir da participação voluntária no processo de votação. Psicologia \& Sociedade, 23(2), 312-324.

Submissão em: 21/06/2015

Revisão em: 27/12/2015

Aceite em: 30/01/2016

\section{Agradecimentos}

À CAPES pelo apoio na forma de bolsa Reuni, à FAPES (processo 69922241/2015) e ao CNPq (processo 308376/2014-5) pelo apoio financeiro.

Everton Faria Meira é graduado em Administração pela Universidade Federal do Espírito Santo. Mestrado e doutorando em Administração pela Universidade Federal do Espírito Santo. Professor do Dep. de Administração da

Universidade Federal do Espírito Santo. Endereço para correspondência: Departamento de Administração - CCJE.

Universidade Federal do Espirito Santo. Av. Fernando Ferrari, 514. CEP 29075-910. Vitória/ES, Brasil. E-mail: evertonmeira@hotmail.com

Marcia Prezotti Palassi é graduada em Administração de Empresas pelo Centro Superior de Ciências Sociais de Vila Velha - UVV. Especialização em Administração de Recursos Humanos pela Faculdade Espírito Santense de Administração - FAESA (1990). Mestrado em Psicologia pela Universidade Federal do Espírito Santo - UFES

(1998). Doutorado em Psicologia Social pela Pontifícia Universidade Católica de São Paulo - PUC. Pós-doutorado em Psicologia Social na Universidad Complutense de Madrid/Espanha. Professora do Programa de Pós-

Graduação em Administração - PPGADM e do Programa de Pós-Graduação em Ciências Sociais - PGCS da Universidade Federal do Espírito Santo - UFES. E-mail: mprezotti@hotmail.com

Alfredo Rodrigues Leite da Silva é graduado em Administração pela Faculdade Espírito Santense de Administração - FAESA. Mestrado em Administração pela Universidade Federal do Espírito Santo - UFES. Doutorado em Administração pela Universidade Federal de Minas Gerais - UFMG. Professor do Programa de Pós-Graduação em Administração - PPGADM da Universidade Federal do Espírito Santo - UFES. E-mail: alfredoufes@gmail.com 